\title{
Male monkeys fight in between-group conflicts as protective parents and reluctant recruits
}

\author{
Arseneau, T Jean M ; Taucher, Anouk-Lisa ; van Schaik, Carel P ; Willems, Erik P
}

DOI: https://doi.org/10.1016/j.anbehav.2015.09.006

Posted at the Zurich Open Repository and Archive, University of Zurich ZORA URL: https://doi.org/10.5167/uzh-119390

Journal Article

Accepted Version

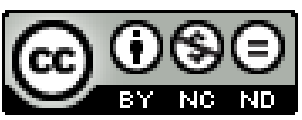

The following work is licensed under a Creative Commons: Attribution-NonCommercial-NoDerivatives 4.0 International (CC BY-NC-ND 4.0) License.

Originally published at:

Arseneau, T Jean M; Taucher, Anouk-Lisa; van Schaik, Carel P; Willems, Erik P (2015). Male monkeys fight in between-group conflicts as protective parents and reluctant recruits. Animal Behaviour, 110:3950.

DOI: https://doi.org/10.1016/j.anbehav.2015.09.006 
T. Jean M. Arseneau, ${ }^{\mathrm{a}, \mathrm{b}, *}$, Anouk-Lisa Taucher ${ }^{\mathrm{a}, \mathrm{b}}$, Carel P. van Schaik ${ }^{\mathrm{a}}$, Erik P. Willems ${ }^{\mathrm{a}, \mathrm{b}}$

$4{ }^{a}$ Anthropological Institute and Museum, University of Zurich, Zurich, Switzerland

$5 \quad$ b Inkawu Vervet Project, Mawana Game Reserve, KwaZulu-Natal, South Africa

6 Received 30 March 2015

7 Initial acceptance 13 May 2015

8 Final acceptance 19 August 2015

9 MS. number: 15-00258R

*Correspondence: T. J. M. Arseneau, Anthropological Institute and Museum, University of Zurich,

11 Winterthurerstrasse 190, Zurich 8057, Switzerland.

12 E-mail address: thelmajeanmarie.arseneau@uzh.ch (T. J. M. Arseneau).

In many social species, group members cooperate to defend a communal home range. Fighting in between-group conflicts carries an opportunity cost, a risk of injury or death, and the possibility of exploitation by free-riding group members. As a result, it is rare that all group members fight in a given between-group conflict, and individual participation in range defence is often highly variable. Thus, to understand the patterns of behaviour observed at the group level, we must first understand the causes of within- and between-individual variability. Although sex differences have been well studied, our

21 understanding of the relative importance of the various mechanisms promoting between-group

22 aggression within a sex is limited. We observed the participation of 22 male vervet monkeys,

23 Chlorocebus aethiops pygerythrus, in 126 between-group conflicts, and then partitioned aggressive acts

24 according to the context in which they occurred. Using this approach, we found evidence that two 
25 mechanisms drive male between-group aggression and, therefore, that individual variability is in part

26 driven by the multiple selective benefits of participation. First, males that were likely to have sired

27 offspring tended to exhibit defensive aggression and were more active when infants were present in the

28 group, suggesting they fight to defend probable offspring. Second, males were more likely to support

29 females in initiating between-group aggression just prior to, and during, the mating season. Female

30 vervet monkeys are able to exert female choice and males that frequently supported female instigators

31 tended to enjoy the highest mating success. These results indicate that males probably use between-

32 group aggression to improve their reputation with choosy females and subsequently maximize their

33 mating success. Our findings indicate that a greater understanding of the evolutionary mechanisms

34 promoting cooperative home range defence can be gained if we consider the context in which acts of

35 between-group aggression occur.

36

37

38 Keywords

39 between-group competition, collective action problem, female choice, paternal care, reputation 
41 In a diverse array of social species, group members cooperate during between-group (BG) conflicts to defend access to space, mating opportunities, offspring or limiting resources such as food, water and shelter (Boydston, Morelli, \& Holekamp, 2001; Hölldobler, 1981; Manson et al., 1991; Mares, Young, \& Clutton-Brock, 2012; Mosser \& Packer, 2009; R. W. Wrangham, 1980). Fighting in BG conflicts is costly because participation carries an opportunity cost, a risk of injury or death, and a risk of being exploited by free-riding group members (Nunn \& Lewis, 2001). Home range defence creates a public good, where all group members benefit from the access to defended resources regardless of whether they contributed to range defence or not. Because individuals that do not participate in home range defence gain the greatest net benefits, selection favours a cheating strategy, and home range defence suffers from a collective action problem (Nunn \& Lewis, 2001; Olson, 1965; Willems, Hellriegel, \& van Schaik, 2013). This problem is avoided when group members are highly related and therefore can gain indirect fitness benefits from cooperating with group members (Nunn \& Lewis, 2001), as in cooperative breeders and eusocial insects. However, even in species in which participation in BG conflicts appears to be collective, individual participation is often highly variable and it is rare that all group members are active (Bonanni, Valsecchi, \& Natoli, 2010; Boydston et al., 2001; Carlson, 1986; Heinsohn \& Packer, 1995; Kitchen, 2006; Nunn \& Deaner, 2004; Zhao \& Tan, 2011). Thus, it is often the case that BG aggression is not truly a collective action involving all members of a social group, but is rather a 'joint action' by a subset of individuals (Willems \& van Schaik, 2015). When action is joint, we should not regard social groups as monolithic units, but instead as complex systems composed of selfish entities (Arrow, McGrath, \& Berdahl, 2000). The patterns of cooperative behaviour observed at the group level are an emergent property, which arise because of the individual benefits gained through participation and the social incentives exchanged among group members.

Individual benefits are gained in the process of producing the public good; conversely, social incentives are benefits that are bestowed on cooperative individuals by their fellow group members (Fig. 
1). Cooperative individuals may gain individual benefits when they have priority of access to the public good or when group members are close kin. In the context of BG conflicts, high-ranking individuals may gain asymmetric benefits and therefore be more likely to participate than other group members (S. A. Altmann, 1962). Participants may gain inclusive fitness benefits via kin selection (Hamilton, 1964), or BG aggression may serve to protect close relatives. Social incentives can be used to directly coerce group members into cooperating, or cooperative individuals may benefit indirectly by improving their reputation with group members (Alexander, 1987; Glowacki \& Wrangham, 2013; Zahavi, 1975). Two potential reputation mechanisms are social prestige and image score, and BG aggression may be used to build reputation with potential coalition partners or potential mates. For the latter to be feasible, females must be able to exert female choice, such that males compete with each other to impress choosy females; this may be the case in multimale groups, or when females are able to transfer between groups in order to access preferred males. In the case of social prestige, participation in BG conflicts functions as an honest and costly signal of genetic quality (Zahavi, 1975). Alternatively, reputation based on image score assumes only that participation in BG conflicts makes the participant a more valued group member (Alexander, 1987; Nowak \& Sigmund, 2005). Determining the relative importance of these various individual benefits and social incentives in driving participation in BG conflicts will provide new insights into a major question in behavioural ecology: given the selective benefits of cheating, how could cooperation evolve, and how is it maintained?

In this paper, we focus on identifying the mechanisms driving male participation in BG conflicts in wild vervet monkeys, Chlorocebus aethiops pygerythrus. Vervet monkeys live in multimale multifemale groups and members of both sexes are active in BG conflicts. Although females are smaller than males, both sexes can initiate BG aggression and, in rare cases, physically attack members of opposing groups. Vervet monkeys are a highly suitable species for investigating individual variability in BG aggression as usually only a handful of group members are active in a given BG conflict, and 
participation is highly variable both within and between individuals. Male BG aggression is particularly interesting because males may gain a variety of selective benefits from it (Fashing, 2001). Males are the dispersing sex in vervet monkeys, and, as a result, kinship benefits are more likely through parental care than kin selection (Fig. 1). Although offspring defence has primarily been seen in species that exhibit infanticide (Grinnell, Packer, \& Pusey, 1995; Kitchen, 2004), BG conflicts can result in infant mortality in this species (Cheney \& Seyfarth, 1987), which indicates that offspring defence could provide fitness benefits to males. Because male fitness is limited by access to receptive females (Trivers, 1972), and male vervet monkeys often try to prevent immigration of other males, mate defence may be an important individual benefit (Cheney, 1981). If so, then males with priority of access to mating opportunities (e.g. high-ranking males) should be more likely to exhibit BG aggression (Cooper, Aureli, \& Singh, 2004; Kitchen, 2004). If males, in defending mates, also end up defending food resources as a by-product, they are said to act as 'Hired Guns' (Fashing, 2001; R. Wrangham \& Rubenstein, 1986). Males may also directly defend food resources to increase the reproductive output of their mates (Williams, Oehlert, Carlis, \& Pusey, 2004), a potentially beneficial strategy since resource availability has been linked to infant survival in vervet monkeys (Cheney \& Seyfarth, 1987; Lee \& Hauser, 1998). Alternatively, males may use BG aggression to enhance their reputation with choosy females, and subsequently increase their mating success. Moderate sexual dimorphism, female choice (Struhsaker, 1967) and the presence of multiple males in a group indicate that there is the potential for reputation effects in this species.

Because male vervet monkeys do not form coalitions, we do not expect males to use BG aggression as a means to build their reputation with potential coalition partners. Similarly, we are unaware of any nonhuman studies showing that rewards and/or punishment are used to manipulate participation in BG conflicts.

The aim of this study was to identify the causes of within- and between-individual variability in BG aggression, in order to determine the relative importance of the various mechanisms driving male 
113 participation in BG conflicts. Although many studies have identified variation in the benefits gained by 114 males and females (Fashing, 2001; Kitchen, 2004, 2006; Van Belle, 2015; Van Belle, Garber, Estrada, \& 115 Di Fiore, 2014), uncovering variability in the selective benefits promoting BG aggression within and 116 between individuals of the same age-sex class has proven more difficult. We are unaware of any studies 117 that show clear evidence that multiple mechanisms are at work within a sex. This lack of evidence may 118 be because only a single selective benefit motivates individuals in many species, or because a different 119 methodological approach is necessary to detect variability when it does exist. Previous studies have 120 typically analysed whether individuals have, or have not, exhibited aggression during BG conflicts (e.g., 121 Cooper et al., 2004; Fashing, 2001; Harris, 2010). However, there may be several acts of BG aggression 122 within a single BG conflict, and because such an approach pools all of these, it inherently treats these 123 independent acts as a homogeneous phenomenon. Doing so may mask within- and between-individual 124 variability in the selective benefits of BG aggression. Alternatively, if within- or between-individual 125 variability does exist, then acts of BG aggression may be motivated by different selective benefits, and 126 the context surrounding each act of BG aggression may provide insight into what those selective benefits 127 are.

To test this supposition, we collected detailed observations of male participation in naturally occurring BG conflicts in a wild population of vervet monkeys. Using this data set, we identified four context-specific types of BG aggression exhibited by males: (1) defensive aggression, in response to BG aggression by the opposing group; (2) repelling prospecting males, which was the act of chasing away extragroup males that engaged in neutral (e.g. sitting in close proximity) or affiliative (e.g. grooming or 133 playing) interactions with group members; (3) proactive aggression, which was BG aggression without a 134 female leader or partner; (4) supporting female instigators, which was when males followed/supported a 135 female leader in initiating BG aggression. 
In this paper, we first examine male participation during BG conflicts as has typically been done

137 in previous studies, treating BG aggression as a homogeneous phenomenon. Second, we examine BG

138 aggression in each of the four contexts (defensive aggression, repelling prospectors, proactive

139 aggression and supporting female instigators) to determine whether such an approach can provide

140 further insight into the relative importance of the various selective benefits that may drive male

141 participation. If any type of BG aggression serves to protect offspring, we predict that it would primarily

142 be exhibited when there are (more) infants in the group, and by males that were likely to be sires of

143 those infants. If males exhibit BG aggression to defend mates, we predict that this type of aggression

144 would be exhibited predominantly by high-ranking males and be more common in the mating season. If

145 BG aggression of any type functions as food defence, we predict that it would primarily be exhibited in

146 seasons when defensible resources are abundant. Last, if males use a given type of BG aggression to

147 build their reputation with female group members, we would expect this type of aggression to be

148 exhibited primarily during the mating season, and that males that frequently exhibit this type of BG

149 aggression should subsequently experience greater mating success.

\section{METHODS}

153 Subjects and Study Site

154 Data were collected on three habituated groups of vervet monkeys at the Mawana Game Reserve $155\left(28^{\circ} 00^{\prime} \mathrm{S}, 31^{\circ} 12^{\prime} \mathrm{E}\right)$, KwaZulu-Natal, South Africa. Groups consisted of 30-56 individuals and the 156 number of adult males per group ranged from one to seven over the study period. All animals in the 157 three focal groups were individually recognized, as were most of the adults in four neighbouring and 158 frequently encountered groups. 
The 22 sampled males were classified as belonging to four different career stages (van

Noordwijk \& van Schaik, 1988) based on their rank and probability of having sired offspring at the time of each BG conflict. Matings were recorded on an all-occurrence basis (J. Altmann, 1974), and although low-ranking males did attempt to mate out of sight of the dominant male, the open habitat and frequent terrestrial behaviour of the vervet monkeys meant that matings by both dominant and subordinate males were easily observed by researchers. Thus, the observed matings should be an unbiased sample of the matings that each male actually obtained. For each of the study groups, we calculated the proportion of the observed matings obtained by each male in a given mating season, and classified males having more than $20 \%$ of the matings as likely sires. Although we did not use genetic analyses to verify paternity in this study, there is no evidence for paternal kin recognition in this species; therefore, the behavioural proxy we used (i.e. the number of matings males procured, relative to other males in their group) most faithfully represents the information on potential paternity available to the males themselves. Our $20 \%$ cutoff was based on the median value of the proportions of matings observed for all males. The mean percentage of matings procured by males below the $20 \%$ cutoff was $7 \%$. On average there were 2.2 males (range 1-3) that were deemed likely sires in each group in a given year, and up to five males with a low probability of having sired offspring ( $<20 \%$ of observed matings). Likely sires were further subdivided into dominant likely sires if they were the alpha male, and subordinate likely sires if they were a subordinate male at the time of the BG conflict. Lastly, uninvested males were subordinate males that had not achieved high mating success in their present group.

To determine whether residency time influenced male BG aggression, we also classified males as being recent immigrants if they had joined their respective groups within the 60 days preceding the BG conflict. This was the maximum length of time that males took to integrate into their group. Similarly, males that would leave their respective groups within the 60 days following the BG conflict were deemed future emigrants. 
Behavioural observations were made between January 2012 and February 2014. Groups were followed an average of $6.5 \mathrm{~h}$ per day, 5 days per week, for a total of $>11000$ observation hours. Participation in BG conflicts was recorded on an all-occurrence basis (J. Altmann, 1974). Because concurrent experimental research employed provisioning (van de Waal, Borgeaud, \& Whiten, 2013), we excluded from our analyses all BG conflicts occurring on days that provisioning had occurred. We defined the onset of a BG encounter when two groups approached within $100 \mathrm{~m}$ of each other or initiated vocal interactions over larger distances. At the onset of a BG encounter we recorded the time and the location with a handheld GPS unit (Garmin GPSMAP64, Garmin Ltd). Throughout the BG conflict we recorded all participation events for each individual in the focal group and also noted the participation of the opposing group's members whenever possible. Between-group encounters were deemed BG conflicts when one or more individuals from either group exhibited aggression to the opposing group. For each aggressive participation event, we recorded the identity of active individuals, the identity of the

197 individual that initiated/led the event, behaviour(s) exhibited, identity of the target individuals (or their sex and age class when their identity was unknown), and whether the aggressive behaviour was proactive (initiated by the focal group) or reactive (in response to aggression by the opposing group). Aggressive behaviours could be directed towards the opposing group as a whole (e.g. running at the 201 group or making aggressive displays and/or vocalizations) or target specific individuals (e.g. chasing or 202 biting).

GPS Data and Home Range Estimation

205 Previous studies have shown that individuals are more likely to exhibit aggression closer to the centre of 206 their home range or in intensely used areas, and as a result groups are more likely to win conflicts in 
207 these locations (Crofoot \& Gilby, 2012; Markham, Alberts, \& Altmann, 2012). To account for this 208 potentially confounding effect of location, we determined both the distance from each BG conflict 209 location to the home range centre and the long-term intensity of use. We deployed a GPS collar (e-obs 210 Type 1C light, e-obs $\mathrm{GmbH}$ ) on one adult female in each group, and programmed it to obtain GPS-fixes 211 every 30 min, from 0500 to 1900 hours, between March 2013 and February 2014. Over this period, 212 utilization distributions were estimated for each group using the Brownian bridge movement model 213 (Horne, Garton, Krone, \& Lewis, 2007) as implemented by (Buchin, Sijben, Arseneau, \& Willems, 214 2012) in R (version 3.0.2, R Core Team, 2014). Fixes from the beginning, and end, of the day that were 215 within $50 \mathrm{~m}$ of the start, and finish, locations, were censored to restrict our calculations to the diurnal conflict location, we determined the local intensity of use from the estimated utilization distribution, and the distance to the home range centroid. Intensity of use values were reciprocal-log transformed in order to stabilize our statistical models and ensure convergence of maximum-likelihood parameter estimates. Although we did not have GPS location data across the entire study period, the observed range use of all three focal groups was stable between years. Thus, areas of higher intensity of use in the period with active GPS loggers suitably represented the longer-term value of an area for the purpose of this study.

\section{Habitat Productivity}

226 As an index of local habitat productivity, we calculated monthly average normalized difference 227 vegetation index (NDVI) values from the MODIS MCD43A4 data set (version 5, processed by NASA's 228 LP DAAC (NASA Land Processes Distributed Active Archive Center (LP DAAC), 2014) and 229 redistributed by WAMIS at http://wamis.meraka.org/za/). The NDVI is a well-established proxy of the amount and vigour of green vegetation, and strongly correlates with field measurements of food 
231 availability and shelter in vervet monkeys (Willems, Barton, \& Hill, 2009). Over the study period,

232 monthly average NDVI values ranged from 0.25 to 0.67 with larger values indicating denser and more

233 photosynthetically active vegetation.

\section{Statistical Analyses}

236 We included male career stage and residency status as independent factors in our analyses of BG 237 aggression. We also included four seasonal factors (the onset of the birth season, number of infants, 238 seasonal resource abundance and mating season), the intensity of use of the BG conflict location, 239 distance to the home range centre and the asymmetry in group size as independent factors. The first 240 infants were typically born in September or October. We included the first month of the birth season (30 241 days following the first birth in the group: yes or no) in our analyses to test whether males were more 242 aggressive when they first became likely sires. We defined the number of infants in the group as the 243 number of individuals less than 3 months old. Monthly NDVI values were included as a proxy of 244 seasonal resource (food and shelter) abundance (Willems et al., 2009), with above-average NDVI values 245 typically occurring between December and May. We classified the mating season as months in which 246 the average mating rate was greater than two matings per 100 observation hours (April to August 2012; 247 April to July 2013). Last, because previous studies have shown that individuals may modulate their 248 participation in BG conflicts according to the relative fighting ability of their group, being active 249 primarily when their group is outnumbered and their participation is most needed (Heinsohn \& Packer, 250 1995; Kitchen, 2006), we also considered the effect that asymmetry in group size had on male 251 participation. Relative group size was defined as the relative number of adults and subadults in the focal 252 group minus the number in the opposing group. We included adults and subadults as these were the two 253 age classes that typically participated aggressively during BG conflicts. 
All statistical analyses were conducted in R (version 3.0.3, R Core Team, 2014) using the lme4 package (version 1.1-4, Bates, Maechler, Bolker, \& Walker, 2014) and nlme packages (version 3.1-113, Pinheiro \& Bates, 2014). In our first analysis, we built a generalized linear mixed model (GLMM) to test the relative importance of the various independent factors (e.g. male career stage, residency, season, location and relative group size) in explaining whether or not males behaved aggressively during BG conflicts. In this first analysis, all aggressive acts were treated as a homogeneous phenomenon as we did not take into account the context in which they occurred. In our second set of analyses we used four separate GLMMs to investigate which factors influenced whether males (1) exhibited defensive instigators during BG conflicts.

In all GLMMs the response variable was binary, and we therefore set a binomial error structure and logit link function in our models. We included male identity nested within group as random effects in all models to account for repeated sampling of individuals (Zuur, Ieno, Walker, Saveliev, \& Smith, 2009). When we tested the effect of male career stage, uninvested males were always coded as the reference category. When both dominant and subordinate likely sires showed a similar pattern of behaviour, but one showed a significant effect and the other only a trend, we pooled all sires, regardless of their rank, and reran the model to determine the overall effect of being a likely father (in each case, both models are presented in the Appendix). Doing so had very little effect on parameter estimates. We tested the significance of five interaction terms (male career stage * month following first birth, male career stage * number of infants, male career stage * monthly average NDVI, male career stage * mating season, and number of infants * relative group size) in each GLMM with likelihood ratio tests $\left(\chi^{2}\right.$ test statistic), comparing the model with only main effects included to the model with each interaction included (Bolker et al., 2009; Zuur et al., 2009). Interactions that did not improve model fit at 
277 the significance level of $\alpha=0.1$ were not retained in the final model. In all analyses, $\alpha$ was set at 0.05 , 278 but we briefly discuss nonsignificant trends $(P<0.10)$ when they are biologically interesting.

To test whether any of the four types of BG aggression were related to male mating success, we used linear mixed-effects models (LMMs). We tested whether the proportion of BG conflicts in which males exhibited each aggression type (between January and the end of the mating season) correlated with their subsequent mating success that year. We excluded males that immigrated at the end of the mating season (were not present for at least three BG conflicts) from these analyses. The response variable, individual daily mating rate, was arcsine-square-root transformed prior to analysis, and we included individual male identity nested within group as a random effect (Zuur et al., 2009).

We based our inferences on full models (plus important interaction effects) rather than using a stepwise procedure to avoid false positives and biased effect size estimates (Forstmeier \& Schielzeth, comparing the final model to the null model (model including intercept and random effects only) using a likelihood ratio test, while the total variance explained $\left(R_{\mathrm{GLMM}(\mathrm{c})}^{2}\right)$ was estimated following the method

293 the marginal rather than conditional $R_{\text {LMM }}^{2}$ because we were only interested in the variance explained by 294 the fixed effects.

\section{Ethical Note}

297 All data collection protocols were approved by local and national authorities, as well as the Ezemvelo 298 KZN Wildlife Ethics Board in South Africa. In the course of this study period we trapped nine adult 299 females in the three main study groups in order to outfit each with a GPS collar. We modified the 
301 rope to trigger the trap and target the desired individual (i.e. an adult female). Once captured, females 302 were tranquillized with ketamine, weighed, and a GPS collar fitted before they were released. After 303 being released in a shady and covered location, females were observed until they had recovered and 304 returned to their group. The weight of GPS collars was $120 \mathrm{~g}$, which is equivalent to approximately $3 \%$ 305 of the body weight of the smallest adult female that we collared. GPS collars were active for 4-5 months 306 before the battery failed; thus, we deployed GPS collars onto three females in each of the three groups to 307 obtain 1 year of continuous movement data.

\section{RESULTS}

311 In total we observed more than $400 \mathrm{BG}$ encounters, half of which escalated into a BG conflict. We 312 restricted our analyses to a subset of 126 BG conflicts in which all independent factors were known. On 313 average, an individual male was only aggressive in a quarter of the BG conflicts that his group 314 experienced, but participation was highly variable among the 22 males (mean proportion of encounters \pm 315 SD: $0.25 \pm 0.20$; Fig. 2). The most frequently observed types of aggression were defensive aggression $316(0.08 \pm 0.12)$, repelling prospecting males $(0.06 \pm 0.08)$ and supporting instigator females $(0.10 \pm 0.10)$. 317 Conversely, males rarely initiated proactive aggression without a female partner $(0.03 \pm 0.05)$.

\section{Treating Acts of BG Aggression as Homogeneous}

320 In our first analysis, in which we did not differentiate between acts of BG aggression within BG 321 conflicts, we found that male career stage was an important predictor of male BG aggression. Dominant 322 likely sires were more likely to behave aggressively during BG conflicts than uninvested males 323 (subordinate males that were unlikely to have sired offspring), particularly when there were more infants 324 in the group (Fig. 3a, Table A1). Subordinate likely sires showed a similar pattern of participation, but 
325 the interaction term just failed to reach statistical significance (Fig. 3a, Table A1). However, when we 326 pooled all likely sires, regardless of their rank, an overall positive interaction between the number of 327 infants in the group and being a likely sire was apparent (Table A2). Males were more likely to be 328 aggressive in the first month of the birth season than during the rest of the year (Table A2), and males 329 tended to exhibit BG aggression more if there were infants in the group and their group was at a 330 numerical disadvantage (Fig. 3b, Table A2). Alternatively, when there were infants in the group and 331 their group was at a numerical advantage, males were the least active in BG conflicts. Thus, males, and 332 likely sires in particular, appeared to be sensitive to the risk that BG conflicts posed to probable 333 offspring. Males that had recently immigrated tended to participate in BG conflicts less frequently than other males (Table A2). We detected no effect of seasonal resource abundance, mating season, the annual intensity of use of the conflict location or the distance to the home range centre on the probability that males were aggressive during BG conflicts (Table A2).

\section{Context 1: Defensive BG Aggression}

In our second set of analyses, we classified acts of BG aggression into four categories according to the context in which the aggression was exhibited. We found that likely sires were more likely to exhibit defensive BG aggression, although dominant and subordinate likely sires did not show the same strength of response. Subordinate likely sires were more likely to reactively defend their group members than uninvested males, while dominant likely sires showed only a tendency to do the same (Table A3).

344 However, when we pooled all likely sires, regardless of their rank, we found that a high likelihood of 345 paternity was associated with higher frequencies of defensive aggression (Table A4). In contrast, 346 dominant males without a high likelihood of paternity showed no greater tendency to exhibit defensive 347 aggression than did uninvested males (Table A4). Males used defensive aggression independent of 348 season, location and relative group size (Table A4). 
Context 2: Repelling Prospecting Males

351 Dominant likely sires showed a stronger tendency to repel prospecting males than subordinate likely 352 sires (Table A5) but overall, males that were likely sires were more likely to exhibit this type of BG 353 aggression than uninvested males (Table A6). There was a weak tendency for males to exhibit BG 354 aggression in this context during seasons of high resource abundance (Table A6). This was the time of 355 year that BG conflicts were frequent and of a long duration, and therefore when males had the most 356 opportunities to prospect. Males repelled prospecting males independent of the immigration status, 357 season, location and relative group size (Table A6).

Context 3: Proactive BG Aggression

360 Proactive aggression was also more likely to be exhibited by likely sires than uninvested males, 361 regardless of whether they were dominant or subordinate (Table A7). In contrast, dominant males 362 without a high likelihood of paternity showed no greater tendency to exhibit proactive aggression than 363 did uninvested males (Table A7). Between-group aggression in this context was rare (Fig. 2), but we 364 never observed recent immigrants exhibiting proactive aggression. We found no significant season or 365 location effects in this context, and relative group size was also unimportant (Table A7).

367 Context 4: Supporting Female Instigators

368 In the context of supporting female instigators, males showed different patterns of BG aggression than 369 they did in the other three contexts. Importantly, males were significantly more likely to support female 370 instigators during the mating season than other times of year (Tables A8, A9). We also found a 371 significant interaction between male career stage and resource abundance, indicating that dominant 372 males tended to start supporting female instigators 2-3 months prior to the onset of the mating season, as 
373 this is the time when NDVI values tended to be greater than 0.5 (Fig. 4, Table A9). This tendency,

374 however, was weaker for dominant likely sires than dominant unlikely sires (Fig. 4, Table A8). We

375 detected no significant effect of the number of infants in the group, location or relative group size (Table

376 A9). There was a weak tendency for males to exhibit this type of aggression during the first month of the

377 birth season (Table A9).

Male BG Aggression and Subsequent Mating Success

380 We found that the propensity to exhibit BG aggression in all four contexts was at least weakly associated 381 with subsequent mating success (Fig. 5). However, only BG aggression in the context of supporting 382 female instigators showed a strong correlation; the frequency that individual males exhibited this type of 383 BG aggression explained approximately a third of the variability in male mating success (LMM:

$384 R_{\mathrm{LMM}(\mathrm{m})}^{2}=0.28, t=3.28, P=0.008$; Fig $\left.5 \mathrm{~d}\right)$. Furthermore, $\mathrm{BG}$ aggression to support female instigators 385 explained almost twice as much variation in the subsequent mating success of individual males than did 386 exhibiting defensive aggression $\left(R_{\mathrm{LMM}(\mathrm{m})}^{2}=0.15, t=2.23, P=0.050\right.$; Fig. 5a), repelling prospectors $387\left(R_{\mathrm{LMM}(\mathrm{m})}^{2}=0.14, t=0.053, P=0.053\right.$; Fig. 5 b) or proactive aggression $\left(R_{\mathrm{LMM}(\mathrm{m})}^{2}=0.15, t=2.26, P=\right.$ $388 \quad 0.047$; Fig. 5c). We observed relatively low mating skew such that on average there were 2.2 males per 389 group that obtained $>20 \%$ of the matings in a given year. Thus, the observed relationship between 390 supporting female instigators and individual mating success was not simply a dominance effect, as there 391 were usually one or two subordinate males that were relatively successful in obtaining mating 392 opportunities.

\section{DISCUSSION}


The aim of this study was to determine the relative importance of various individual benefits and social incentives in modulating male aggression during BG conflicts. By considering the social and ecological context surrounding each act of BG aggression, we found evidence for two selective benefits of male participation in BG conflicts. Our findings suggest that likely sires employed an offspring defence strategy, and that reputation effects probably promote male support of female instigators during and just prior to the onset of the mating season. We found little evidence that males fight in BG conflicts to directly defend food or mates, and, unlike other studies (e.g., Crofoot, Gilby, Wikelski, \& Kays, 2008; Markham et al., 2012), we detected no effect of location.

\section{Evidence for Offspring Defence}

When we examined BG aggression as a homogeneous behavioural phenomenon, we found that likely sires were those most likely to participate in BG conflicts, indicating that offspring protection may be an important selective benefit of male BG aggression in vervet monkeys. Males were more likely to exhibit BG aggression when there were (more) infants present, and when being at a numerical disadvantage could increase the risk of injury or death for group members (Mosser \& Packer, 2009; Sillero-Zubiri \& Macdonald, 1998). In many of the BG conflicts that we observed, the group that was at a numerical disadvantage made little attempt to defend a given location, and fled as the larger group approached. On numerous occasions we observed that small infants were at risk of being left behind, presumably when they had strayed too far from their mothers and could not be collected quickly as the group fled. When left behind, infants were attacked by members of the opposing group; as has also been reported in other studies (Cheney \& Seyfarth, 1987), these attacks could result in death. To mitigate this risk, males from numerically inferior groups often ran to meet the opposing group and exhibited defensive aggression, seemingly to ensure that their fleeing group members escaped safely. Conversely, the reduced need for males in larger groups to respond defensively may explain why we found that males in numerically 
superior groups were less likely to participate aggressively during BG conflicts when there were infants in the group. Together, anecdotal and empirical evidence supports the hypothesis that escalated BG conflicts pose a risk to potential offspring, such that likely sires may gain fitness benefits by acting as protective parents.

Males often chase away extragroup males that are attempting to affiliate with group members during BG encounters, and this tendency has been cited as evidence for mate defence in vervet monkeys (Cheney, 1981). Because dominant males typically experienced the greatest mating success, we expected that they, rather than likely sires, would exhibit aggression in this context if prospecting males were perceived primarily as mating competitors. However, we found it was likely sires that were most likely to repel prospecting males, suggesting that the latter are not perceived as future competition, but rather as a threat to potential offspring. Anecdotally, prospecting males were often tolerated in close proximity for long periods, and curious juveniles were those most likely to approach closely and interact with them. It was often after a conflict between juveniles and prospecting males that the latter were chased away.

Previous evidence of offspring defence has primarily been found in species with high paternity certainty and frequent infanticide (e.g., Kitchen, 2004; Wich, Assink, \& Sterck, 2004). To our knowledge, our results are the first to indicate that male BG aggression can function as paternal care in a species with multimale groups and low paternity certainty. In the absence of kin recognition, males may evaluate their probability of paternity based on their past mating success (Moscovice et al., 2010), and when BG conflicts pose a threat to offspring survival, males may gain fitness benefits by defending likely offspring, even in the face of paternity uncertainty.

\section{Evidence for Mate Defence}


443 The only context in which we saw a significant mating season effect was in supporting female

444 instigators. While this finding may superficially seem to support a mate defence strategy, it is unlikely

445 given other evidence. If male aggression during the mating season provided an individual benefit, we

446 would expect that males would be equally as likely to exhibit this type of aggression without a female

447 partner; however, proactive BG aggression was extremely rare, and did not show the same seasonal

448 pattern. Thus, it seems likely that an alternative mechanism can better explain this mating season effect.

\section{Evidence for Food Defence}

451 Resource availability, as indexed by NDVI, had a significant influence on the participation of dominant

452 males in the context of supporting female instigators. Again, given that proactive BG aggression was

453 rare, and did not show the same seasonal pattern, it is unlikely that dominant males exhibit this type of

454 aggression to defend food directly, and that an alternative explanation is required for this interaction 455 term.

457 Evidence for a Reputation Effect

458 We found a significant effect of mating season on the tendency of males to support female instigators.

459 Furthermore, dominant males tended to start exhibiting this type of BG aggression a few months in 460 advance of the mating season. This period (i.e. approximately December to February) is typically 461 characterized by the presence of high-quality fruits and high NDVI values, and is when females were 462 most active in BG conflicts. Given that males that displayed this type of BG aggression were following 463 female leaders, and therefore cooperating with females to defend valuable resources, there is a strong 464 possibility that this type of BG aggression is motivated by social incentives rather than individual 465 benefits. Indirect social incentives (i.e. reputation effects) are a feasible mechanism for promoting male 466 participation in BG conflicts in this species because of the extent to which females can choose their 
mating partners. Females were often observed to refuse matings with both dominant and subordinate males, regardless of differences in body size. Some males were frequently denied copulations, while others were almost never refused, indicating that females have preferences among male group members. Furthermore, male mating success was strongly related to the proportion of BG conflicts in which they had supported female instigators. Together, these findings suggest that males probably support females in fighting for valuable resources as a means of building a good reputation, the benefits of which can be reaped during the subsequent mating season. In species wherefemales are able to use social incentives to exert leverage over males, cooperation may be sexually selected for through female preferences for cooperative males, and males would more accurately be characterized as 'Reluctant Recruits' than 'Hired Guns'.

Although other authors have previously proposed that males may use participation in BG conflicts as a means of building their reputation with female group members (Fashing, 2001; Steenbeek, 1999), we present the first evidence, outside of humans, that BG aggression can be associated with increased mating success (Chagnon, 1988; Glowacki \& Wrangham, 2015; Glowacki \& Wrangham, 2013). To further delineate which reputation mechanism best explains the patterns of behaviour observed in vervet monkeys (i.e. social prestige versus image score), future studies would have to determine whether male BG aggression is an honest signal of male quality (Bergmüller, Johnstone, Russell, \& Bshary, 2007).

In this study, we demonstrated that apparent food or mate defence is not easily interpreted in species with female choice. Similar caution should be taken in interpreting findings in species in which females can disperse to access preferred males, or in which group members form coalitions. In such cases, seasonal variability in participation could indicate either that BG aggression is driven by individual benefits, or that individuals fight in $\mathrm{BG}$ conflicts to improve their reputation with group members. When working on species in which reputation effects may influence BG aggression, it is 
491 important to consider both the ecological and the social context in which individuals participate. Social

492

493 494

495

496

497

498

499

500

501

502

503

504

505

506

507

508

509

510

511

512

513

514

context could be 'with whom individuals cooperate' during BG conflicts, as was examined in this study, or 'whose presence' influences individual participation (e.g., Meunier, Molina-Vila, \& Perry, 2012).

\section{Elucidating Individual Variability by Considering Context}

Despite the important role that individual variability plays in overcoming collective action problems in theoretical models (Gavrilets \& Fortunato, 2014), we are unaware of any study on BG conflict that illustrates that multiple selective benefits promote male BG aggression. In our first analysis, we did not differentiate between acts of aggression within BG conflicts; thus all acts of aggression were treated as a homogeneous phenomenon. With this approach, we only detected an offspring defence strategy,

probably because it was the most frequently expressed mechanism. It was only when we partitioned acts of BG aggression according to context that we elucidated an alternative strategy, namely acting as a

'Reluctant Recruit' in order to build a good reputation.

If BG conflicts pose a risk to infants (as was observed in this study, as well as Cheney, 1987), escalating BG conflicts could have fitness consequences for males that are likely to have sired offspring. Indeed, we saw that likely sires were more likely to exhibit reactive aggression, becoming involved in the BG conflict only when the opposing group was being aggressive rather than initiating BG aggression themselves. Alternatively, failing to support females in instigating BG aggression could negatively influence their reputation, and they may experience lower mating success in the following mating season as a result. Thus, likely sires may face a trade-off between their future mating success and the safety of their current probable offspring. Depending on their probability of paternity, the season and their ability to fight in BG conflicts, individual males probably experience a unique set of costs and benefits from participating or defecting. The observed 'group behaviour' in any given BG conflict emerges from the sum total of the decisions made by each individual group member. As a result, the public good of home 
515 range defence can be produced by different individuals, in different seasons or even at different times 516 within a single BG conflict. Our findings highlight that investigations of group level cooperation must 517 quantify the various selective benefits that influence the decisions of all group members, and not only 518 the selective benefit that is most frequently expressed. Collective action problems can pose a significant 519 challenge to group level cooperation (Nunn \& Lewis, 2001; Willems et al., 2013), and our study has 520 advanced our understanding of the mechanisms by which collective action problems may be averted. 521 However, a comprehensive examination of group level cooperation requires an understanding of not just 522 the selective benefits driving male participation, but also female BG aggression, as well as the factors 523 influencing the effectiveness of cooperation between group members with diverging interests. Such 524 investigations will enrich our understanding of the mechanisms by which BG conflict exerts selective 525 pressure on the evolution of cooperation in social species, including our own (Bowles, 2009; van Schaik, 526 1983; R. W. Wrangham, 1980). 


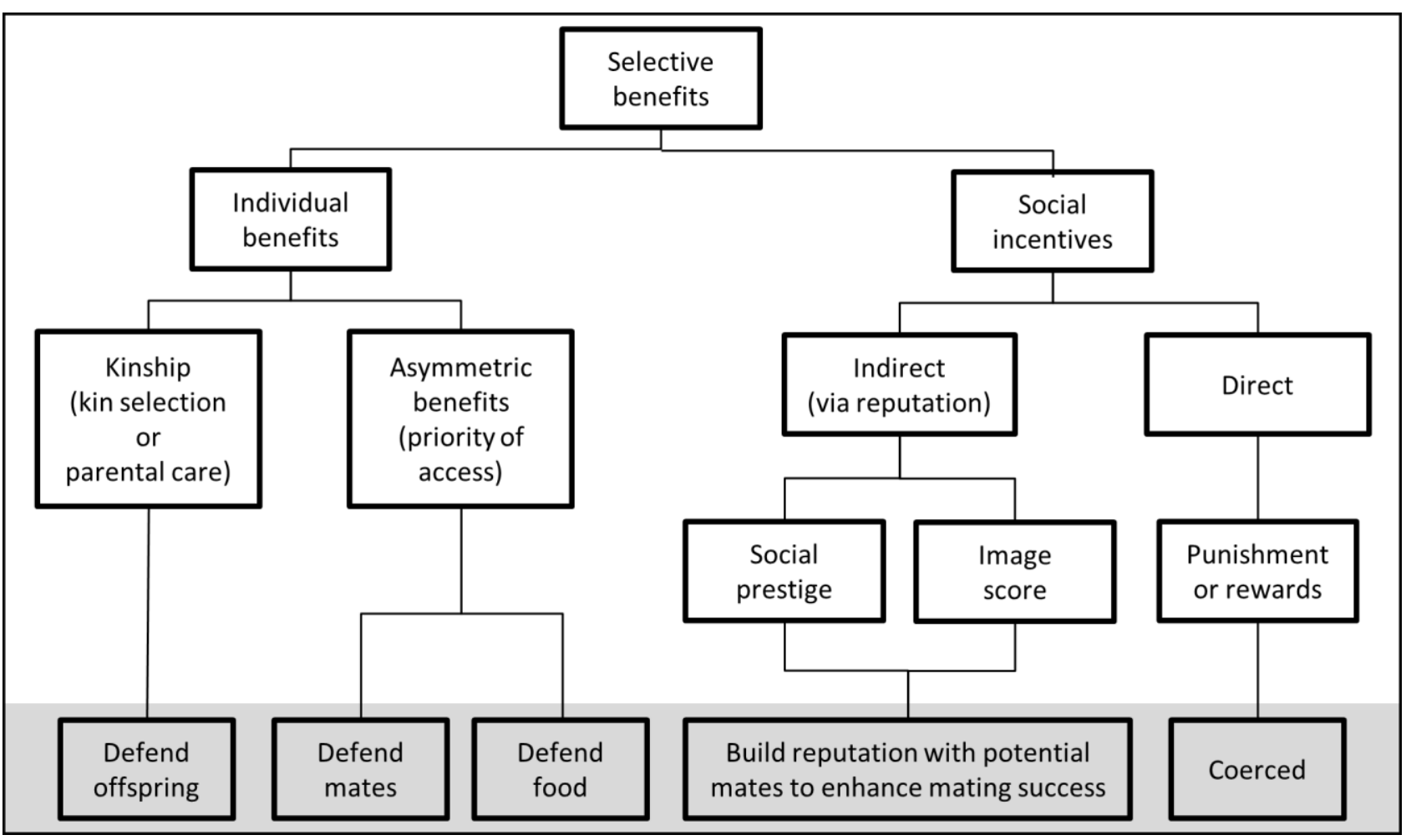

541 Figure 1. Potential selective benefits of cooperation in a social group (white background) (adapted from

542 Bshary \& Bergmüller, 2008; Fashing, 2001; Nunn \& Lewis, 2001) and associated reasons for male

543 vervet monkeys' participation in between-group conflicts (grey background). 


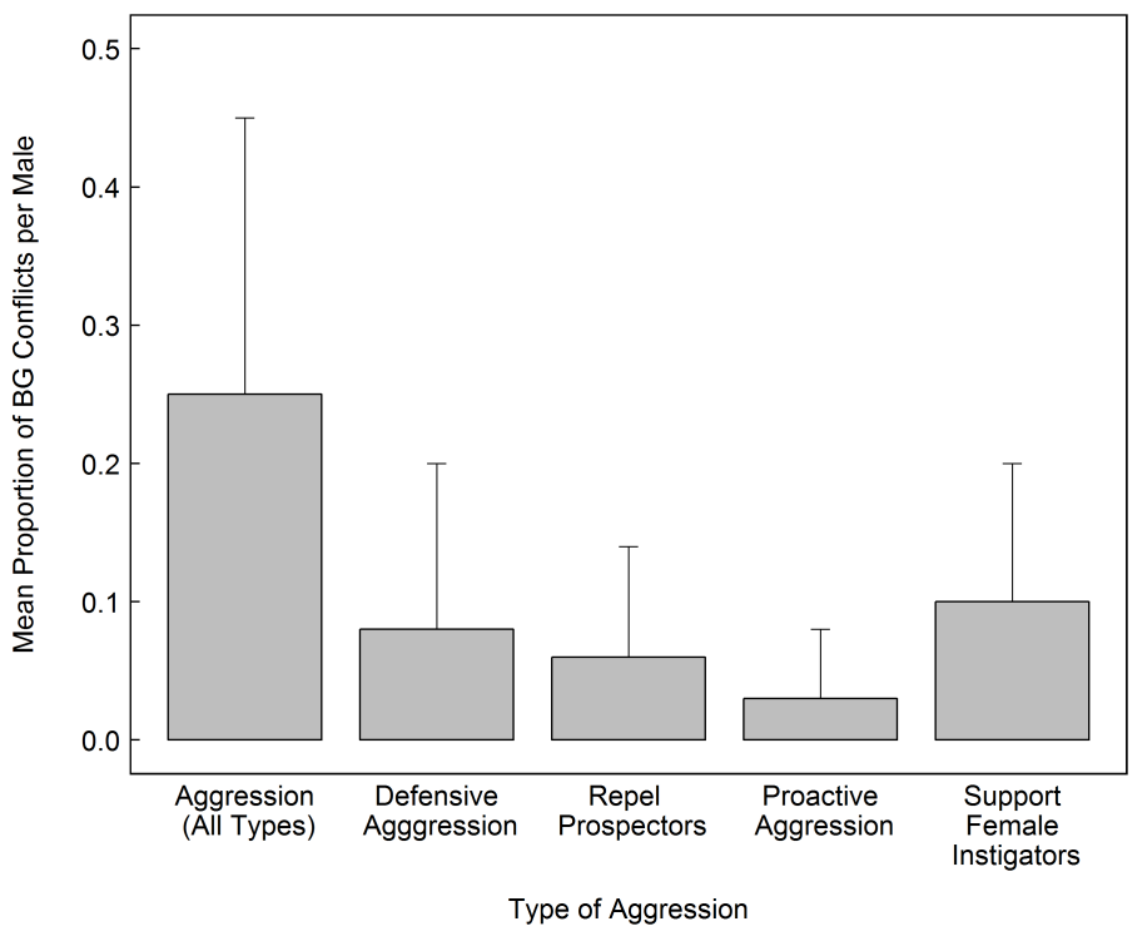

545

546 Figure 2. Mean proportion of between-group conflicts in which males participated aggressively and 547 exhibited each type of context-specific, between-group (BG) aggression. Error bars depict SD. 


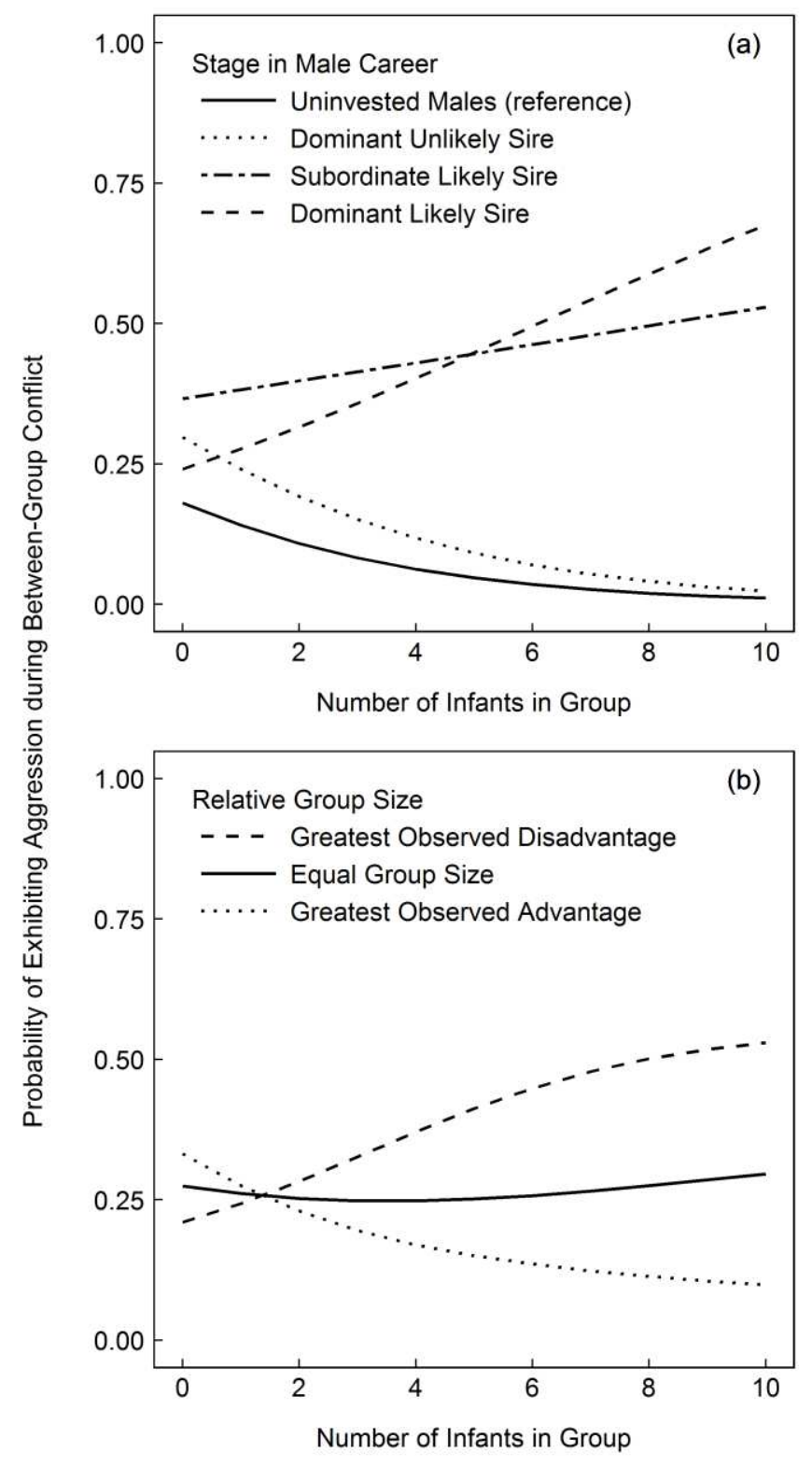

550 Figure 3. Probability of a male participating aggressively during between-group (BG) conflicts as a

551 function of (a) the interaction between male career stage and number of infants in the group and (b) the

552 interaction between relative group size and the number of infants in the group. Prediction lines were

553 obtained by plotting GLMM predictions (Table A1), setting all additional predictor variables to their

554 mean values. In (b), we averaged predicted probabilities across the four categories of male career stage

555 to illustrate the expected probability of aggression for an average male in our population. 


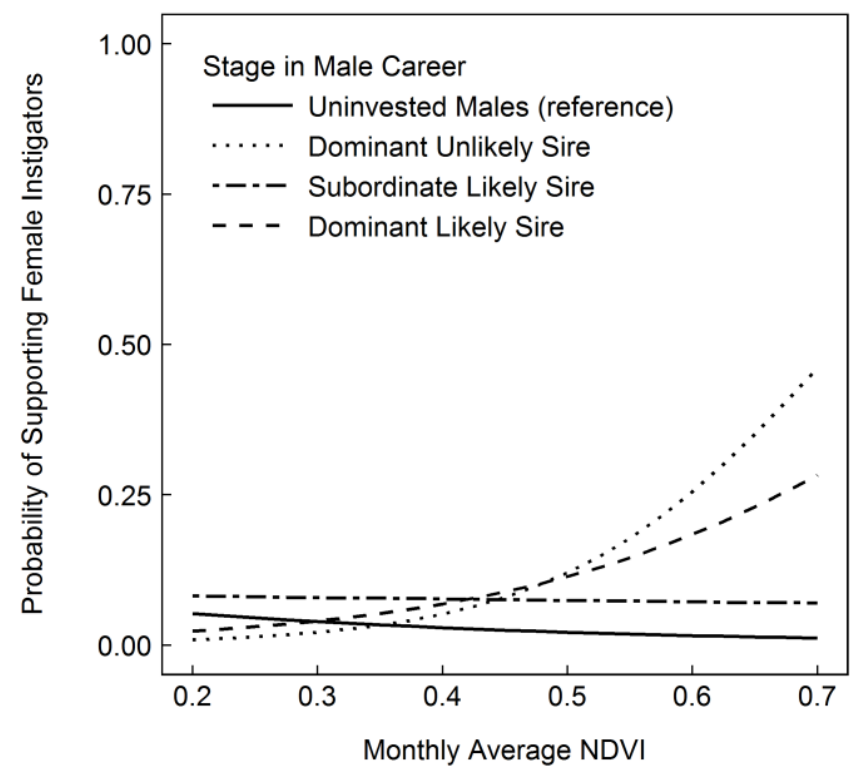

557

558 Figure 4. Probability that males supported female instigators during between-group conflicts, as a

559 function of the interaction between male career stage and the monthly average NDVI values, a proxy of 560 seasonal resource abundance. Prediction lines were obtained by plotting GLMM predictions (Table A8), 561 setting all additional predictor variables to their mean values. 

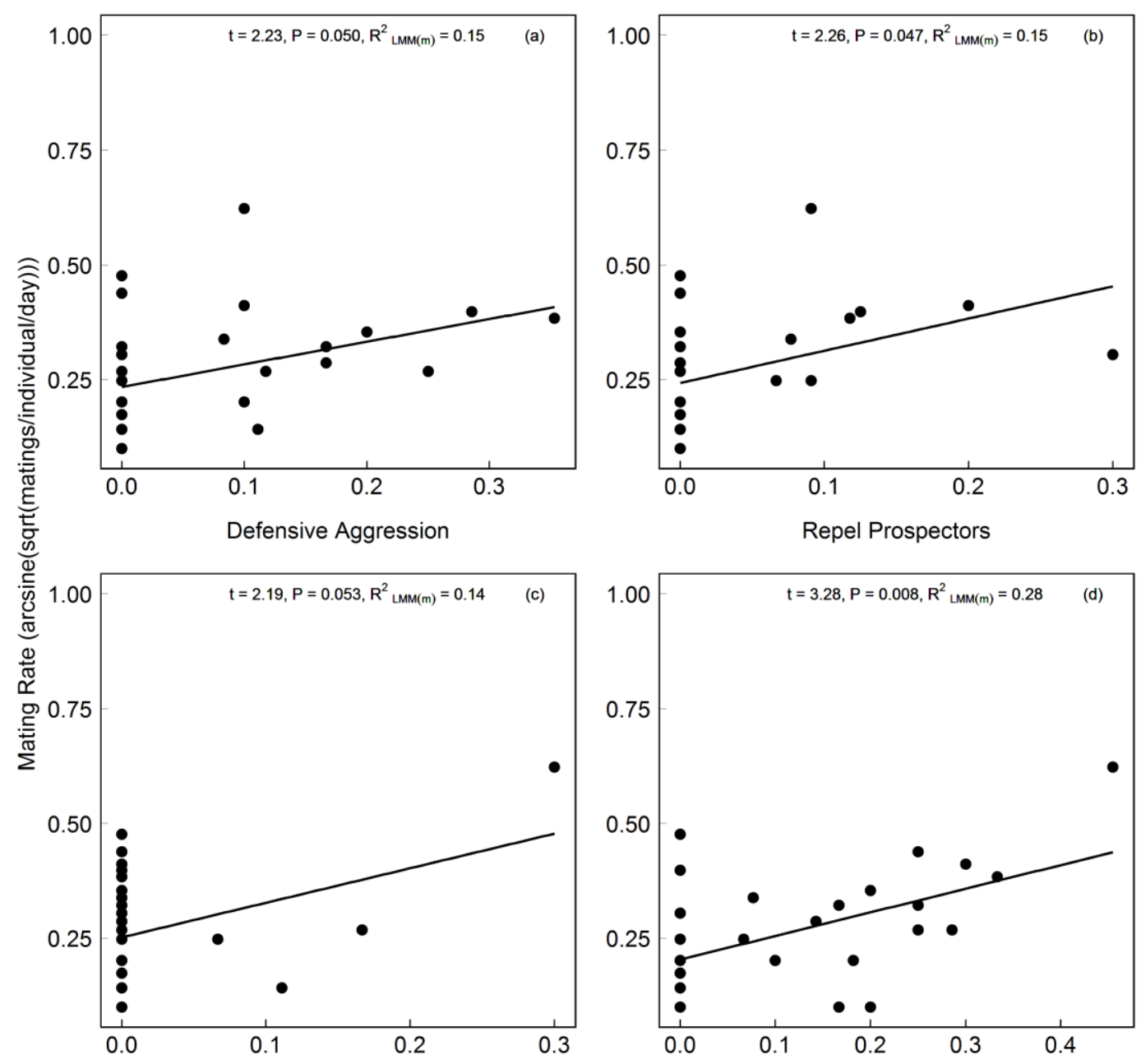

Proactive Aggression

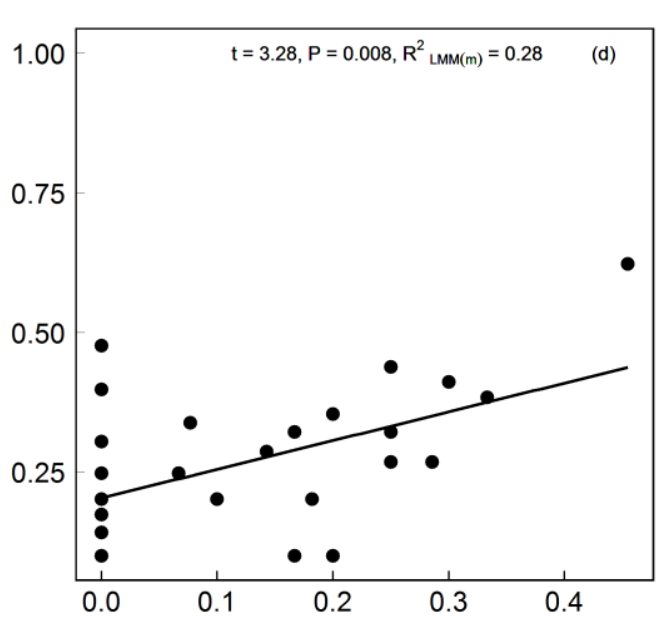

Proportion of BG Conflicts that Males Exhibited each Aggression Type

564 Figure 5. Linear mixed-effects models of the relationship between the proportion of between-group

565 (BG) encounters that males (a) exhibited defensive aggression, (b) repelled prospectors, (c) exhibited 566 proactive aggression and (d) supported female instigators and their subsequent mating success. Each 567 male's daily mating rates were arcsine-square-root transformed prior to analyses. 


\section{Acknowledgments}

This research was supported by a Sinergia grant (CRS133_133040 to C.v.S.) from the Swiss National Science Foundation, the University of Zurich's Forschungskredit (to E.W.) and the Claraz-Stiftung (to E.W.). We are grateful to K. van der Walt for permission to conduct the study at the Mawana Game Reserve and A. Driescher for support in the field. We thank E. van de Waal, C. Borgeaud, S. Mercier, M. Alvino, F. de Antonio, A. Basetti, A. Bono, Y. Bouquet, M. Blaser, A. van Blerk, N. Caduff, M. Chretien, K. Gordon, H. Ismail, B. Jankowiak, K. van Leeuwen, M. Mignini, Z. Mills, T. Montgomery, E. Mueller, K. Neldner, Y. Rothacher, J. Rosen, T. Sharkey, J. Spiby, K. Vega, F. Villa, L. Violetti, S. Watson, J. Watzek, T. White and T. Zimmerman for assistance in data collection. We are grateful to two anonymous referees, whose constructive criticism greatly improved the manuscript.

\section{References}

Alexander, R. D. (1987). The biology of moral systems. Hawthorne, USA: Transaction Publishers.

Altmann, J. (1974). Observational study of behavior: sampling methods. Behaviour, 49(3/4), 227-267. doi: $10.2307 / 4533591$

Altmann, S. A. (1962). A field study of the sociobiology of rhesus monkeys, Macaca mulatta. Annals of the New York Academy of Sciences, 102(2), 338-435. doi: 10.1111/j.1749-6632.1962.tb13650.x

Arrow, H., McGrath, J. E., \& Berdahl, J. L. (2000). Small groups as complex systems: formation, coordination, development, and adaptation. Thousand Oaks, USA: Sage Publications.

Bates, D., Maechler, M., Bolker, B., \& Walker, S. (2014). Ime4: Linear mixed-effects models using Eigen and S4, from http://CRAN.R-project.org/package=Ime4

Bergmüller, R., Johnstone, R. A., Russell, A. F., \& Bshary, R. (2007). Integrating cooperative breeding into theoretical concepts of cooperation. Behavioural Processes, 76(2), 61-72. doi: 10.1016/j.beproc.2007.07.001

Bolker, B. M., Brooks, M. E., Clark, C. J., Geange, S. W., Poulsen, J. R., Stevens, M. H. H., \& White, J.-S. S. (2009). Generalized linear mixed models: a practical guide for ecology and evolution. Trends in Ecology \& Evolution, 24(3), 127-135. doi: 10.1016/j.tree.2008.10.008 
Bonanni, R., Valsecchi, P., \& Natoli, E. (2010). Pattern of individual participation and cheating in conflicts between groups of free-ranging dogs. Animal Behaviour, 79(4), 957-968. doi: 10.1016/j.anbehav.2010.01.016

Bowles, S. (2009). Did warfare among ancestral hunter-gatherers affect the evolution of human social behaviors? Science, 324(5932), 1293-1298. doi: 10.1126/science.1168112

Boydston, E. E., Morelli, T. L., \& Holekamp, K. E. (2001). Sex differences in territorial behavior exhibited by the spotted hyena (Hyaenidae, Crocuta crocuta). Ethology, 107(5), 369-385. doi: 10.1046/j.14390310.2001.00672.x

Bshary, R., \& Bergmüller, R. (2008). Distinguishing four fundamental approaches to the evolution of helping. Journal of Evolutionary Biology, 21(2), 405-420. doi: 10.1111/j.1420-9101.2007.01482.x

Buchin, K., Sijben, S., Arseneau, T. J. M., \& Willems, E. P. (2012). Detecting movement patterns using Brownian bridges. Paper presented at the Proceedings of the 20th International Conference on Advances in Geographic Information Systems, Redondo Beach, California, Nov. 2012.

Carlson, A. (1986). Group territoriality in the rattling cisticola, Cisticola chiniana. Oikos, 47(2), 181-189. doi: $10.2307 / 3566044$

Chagnon, N. A. (1988). Life histories, blood revenge, and warfare in a tribal population. Science 239(4843), 985992. doi: $10.1126 /$ science.239.4843.985

Cheney, D. L. (1981). Intergroup encounters among free-ranging vervet monkeys. Folia Primatologica, 35(2-3), 124-146. doi: 10.1159/000155970

Cheney, D. L. (1987). Interactions and relationships between groups. In B. B. Smuts, D. L. Cheney, R. M. Seyfarth, R. Wrangham \& T. T. Struhsaker (Eds.), Primate societies (pp. 267-281). Chicago, USA: University of Chicago Press.

Cheney, D. L., \& Seyfarth, R. M. (1987). The influence of intergroup competition on the survival and reproduction of female vervet monkeys. Behavioral Ecology and Sociobiology, 21(6), 375-386. doi: 10.1007/BF00299932

Cooper, M. A., Aureli, F., \& Singh, M. (2004). Between-group encounters among bonnet macaques (Macaca radiata). Behavioral Ecology and Sociobiology, 56(3), 217-227. doi: 10.1007/s00265-004-0779-4

Crofoot, M. C., \& Gilby, I. C. (2012). Cheating monkeys undermine group strength in enemy territory. Proceedings of the National Academy of Sciences, 109(2), 501-505. doi: 10.1073/pnas.1115937109

Crofoot, M. C., Gilby, I. C., Wikelski, M. C., \& Kays, R. W. (2008). Interaction location outweighs the competitive advantage of numerical superiority in Cebus capucinus intergroup contests. Proceedings of the National Academy of Sciences, 105(2), 577-581. doi: 10.1073/pnas.0707749105 
Fashing, P. J. (2001). Male and female strategies during intergroup encounters in guerezas (Colobus guereza): evidence for resource defense mediated through males and a comparison with other primates. Behavioral Ecology and Sociobiology, 50(3), 219-230. doi: 10.1007/s002650100358

Forstmeier, W., \& Schielzeth, H. (2011). Cryptic multiple hypotheses testing in linear models: overestimated effect sizes and the winner's curse. Behavioral Ecology and Sociobiology, 65(1), 47-55. doi: $10.1007 / \mathrm{s} 00265-010-1038-5$

Gavrilets, S., \& Fortunato, L. (2014). A solution to the collective action problem in between-group conflict with within-group inequality. [Article]. Nature Communications, 5, 1-11. doi: 10.1038/ncomms4526

Glowacki, L., \& Wrangham, R. (2015). Warfare and reproductive success in a tribal population. Proceedings of the National Academy of Sciences, 112(2), 348-353. doi: 10.1073/pnas.1412287112

Glowacki, L., \& Wrangham, R. W. (2013). The role of rewards in motivating participation in simple warfare. Human Nature, 24(4), 444-460. doi: 10.1007/s12110-013-9178-8

Grinnell, J., Packer, C., \& Pusey, A. E. (1995). Cooperation in male lions: kinship, reciprocity or mutualism? Animal Behaviour, 49(1), 95-105. doi: 10.1016/0003-3472(95)80157-X

Grobler, J. P., \& Turner, T. R. (2010). A novel trap design for the capture and sedation of vervet monkeys (Chlorocebus aethiops). South African Journal of Wildlife Research, 40(2), 163-168. doi: 10.3957/056.040.0208

Hamilton, W. D. (1964). The genetical evolution of social behaviour. I. Journal of Theoretical Biology, 7(1), 1-16. doi: 10.1016/0022-5193(64)90038-4

Harris, T. R. (2010). Multiple resource values and fighting ability measures influence intergroup conflict in guerezas (Colobus guereza). Animal Behaviour, 79(1), 89-98. doi: 10.1016/j.anbehav.2009.10.007

Heinsohn, R., \& Packer, C. (1995). Complex cooperative strategies in group-territorial African lions. Science, 269(5228), 1260-1262. doi: 10.1126/science.7652573

Hölldobler, B. (1981). Foraging and spatiotemporal territories in the honey ant Myrmecocystus mimicus Wheeler (Hymenoptera: Formicidae). Behavioral Ecology and Sociobiology, 9(4), 301-314. doi: 10.2307/4599451

Horne, J. S., Garton, E. O., Krone, S. M., \& Lewis, J. S. (2007). Analyzing animal movements using Brownian bridges. Ecology, 88(9), 2354-2363. doi: 10.1890/06-0957.1

Kitchen, D. M. (2004). Alpha male black howler monkey responses to loud calls: effect of numeric odds, male companion behaviour and reproductive investment. Animal Behaviour, 67(1), 125-139. doi: 10.1016/j.anbehav.2003.03.007

Kitchen, D. M. (2006). Experimental test of female black howler monkey (Alouatta pigra) responses to loud calls from potentially infanticidal males: Effects of numeric odds, vulnerable offspring, and companion behavior. American Journal of Physical Anthropology, 131(1), 73-83. doi: 10.1002/ajpa.20392 
Lee, P. C., \& Hauser, M. D. (1998). Long-term consequences of changes in territory quality on feeding and reproductive strategies of vervet monkeys. Journal of Animal Ecology, 347-358.

Manson, J. H., Wrangham, R. W., Boone, J. L., Chapais, B., Dunbar, R. I. M., Ember, C. R., . . Worthman, C. M. (1991). Intergroup aggression in chimpanzees and humans. Current Anthropology, 32(4), 369-390. doi: $10.2307 / 2743814$

Mares, R., Young, A. J., \& Clutton-Brock, T. H. (2012). Individual contributions to territory defence in a cooperative breeder: weighing up the benefits and costs. Proceedings of the Royal Society B: Biological Sciences, 279(1744), 3989-3995. doi: 10.1098/rspb.2012.1071

Markham, A. C., Alberts, S. C., \& Altmann, J. (2012). Intergroup conflict: ecological predictors of winning and consequences of defeat in a wild primate population. Animal Behaviour, 84(2), 399-403. doi: 10.1016/j.anbehav.2012.05.009

Meunier, H., Molina-Vila, P., \& Perry, S. (2012). Participation in group defence: proximate factors affecting male behaviour in wild white-faced capuchins. Animal Behaviour, 83(3), 621-628. doi: 10.1016/j.anbehav.2011.12.001

Moscovice, L. R., Di Fiore, A., Crockford, C., Kitchen, D. M., Wittig, R., Seyfarth, R. M., \& Cheney, D. L. (2010). Hedging their bets? Male and female chacma baboons form friendships based on likelihood of paternity. Animal Behaviour, 79(5), 1007-1015. doi: 10.1016/j.anbehav.2010.01.013

Mosser, A., \& Packer, C. (2009). Group territoriality and the benefits of sociality in the African lion, Panthera leo. Animal Behaviour, 78(2), 359-370. doi: 10.1016/j.anbehav.2009.04.024

Nakagawa, S., \& Schielzeth, H. (2013). A general and simple method for obtaining $R^{2}$ from generalized linear mixed-effects models. Methods in Ecology and Evolution, 4(2), 133-142. doi: 10.1111/j.2041210x.2012.00261.x

NASA Land Processes Distributed Active Archive Center (LP DAAC). (2014). MODIS MCD43A4 from USGS/Earth Resources Observation and Science (EROS) Center) https://Ipdaac.usgs.gov/dataset_discovery/modis/modis_products_table/mcd43a4

Nowak, M. A., \& Sigmund, K. (2005). Evolution of indirect reciprocity. [10.1038/nature04131]. Nature, 437(7063), 1291-1298. doi: 10.1038/nature04131

Nunn, C. L., \& Deaner, R. O. (2004). Patterns of participation and free riding in territorial conflicts among ringtailed lemurs (Lemur catta). Behavioral Ecology and Sociobiology, 57(1), 50-61. doi: 10.1007/s00265004-0830-5

Nunn, C. L., \& Lewis, R. J. (2001). Cooperation and collective action. In R. Noe, J. A. R. A. M. van Hooff \& P. Hammerstein (Eds.), Economics in Nature (pp. 42-66). Cambridge, UK: Cambridge University Press. 
Olson, M. (1965). The logic of collective action: Public goods and the theory of groups (Vol. 124). Cambridge, USA: Harvard University Press.

Pinheiro, J., \& Bates, D. (2014). Nonlinear mixed-effects models, from http://cran.rproject.org/web/packages/nlme/index.html

R Core Team. (2014). R: a language and environment for statistical computing, from http://www.R-project.org/ Sillero-Zubiri, C., \& Macdonald, D. W. (1998). Scent-marking and territorial behaviour of Ethiopian wolves Canis simensis. Journal of Zoology, 245(3), 351-361. doi: 10.1111/j.1469-7998.1998.tb00110.x

Steenbeek, R. (1999). Tenure related changes in wild Thomas's langurs I: between-group interactions. Behaviour, 136(5), 595-625. doi: 10.1163/156853999501487

Struhsaker, T. T. (1967). Social structure among vervet monkeys (Cercopithecus aethiops). Behaviour, 29(2/4), 83-121. doi: $10.2307 / 4533186$

Trivers, R. L. (1972). Parental investment and sexual selection. In B. Campbell (Ed.), Sexual selection and the descent of man (pp. 136-179). Chicago, USA: Aldine Publishing Company.

Van Belle, S. (2015). Female participation in collective group defense in black howler monkeys (Alouatta pigra). American Journal of Primatology, 77(6), 595-604. doi: 10.1002/ajp.22380

Van Belle, S., Garber, P. A., Estrada, A., \& Di Fiore, A. (2014). Social and genetic factors mediating male participation in collective group defence in black howler monkeys. Animal Behaviour, 98, 7-17. doi: 10.1016/j.anbehav.2014.09.023

van de Waal, E., Borgeaud, C., \& Whiten, A. (2013). Potent social learning and conformity shape a wild primate's foraging decisions. Science, 340(6131), 483-485. doi: 10.1126/science.1232769

van Noordwijk, M. A., \& van Schaik, C. P. (1988). Male careers in Sumatran long-tailed macaques (Macaca fascicularis). Behaviour, 107(1/2), 24-43. doi: 10.2307/4534717

van Schaik, C. P. (1983). Why Are Diurnal Primates Living in Groups? Behaviour, 87(1), 120-144. doi: doi:10.1163/156853983X00147

Wich, S. A., Assink, P. R., \& Sterck, E. H. M. (2004). Thomas langurs (Presbytis thomasi) discriminate between calls of young solitary versus older group-living males: a factor in avoiding infanticide? Behaviour, 141(1), 41-51. doi: $10.2307 / 4536111$

Willems, E. P., Barton, R. A., \& Hill, R. A. (2009). Remotely sensed productivity, regional home range selection, and local range use by an omnivorous primate. Behavioral Ecology, 20(5), 985-992. doi: 10.1093/beheco/arp087

Willems, E. P., Hellriegel, B., \& van Schaik, C. P. (2013). The collective action problem in primate territory economics. Proceedings of the Royal Society B: Biological Sciences, 280(1759), 1-7. doi: $10.1098 /$ rspb.2013.0081 
732 Willems, E. P., \& van Schaik, C. P. (2015). Collective action and the intensity of between-group competition in 733 nonhuman primates. Behavioral Ecology, 26(2), 625-631. doi: 10.1093/beheco/arv001

734 Williams, J. M., Oehlert, G. W., Carlis, J. V., \& Pusey, A. E. (2004). Why do male chimpanzees defend a group range? Animal Behaviour, 68(3), 523-532. doi: 10.1126/science.327542

736 737 738 739 740 741 742 743 744 745 746 747 748 749 750 751 752 753 754 755 756 757 758 759
Wrangham, R., \& Rubenstein, D. I. (1986). Social evolution in birds and mammals. In D. I. Rubenstein \& R. Wrangham (Eds.), Ecology and social evolution: birds and mammals (pp. 452-470). Princeton, USA: Princeton University Press.

Wrangham, R. W. (1980). An ecological model of female-bonded primate groups. Behaviour, 75(3-4), 262-300. doi: $10.1163 / 156853980 \times 00447$

Zahavi, A. (1975). Mate selection - A selection for a handicap. Journal of Theoretical Biology, 53(1), 205-214. doi: 10.1016/0022-5193(75)90111-3

Zhao, Q., \& Tan, C. L. (2011). Inter-unit contests within a provisioned troop of Sichuan snub-nosed monkeys (Rhinopithecus roxellana) in the Qinling Mountains, China. American Journal of Primatology, 73(3), 262269. doi: 10.1002/ajp.20892

Zuur, A. F., leno, E. N., Walker, N. J., Saveliev, A. A., \& Smith, G. M. (2009). Mixed effects models and extensions in ecology with R. New York, USA: Springer Science+Business Media. 
Table A1

763 Factors affecting the probability that males were aggressive (aggression as a homogeneous phenomenon) during

764 between-group conflicts, after nonsignificant interaction terms were removed from the model

\begin{tabular}{lcccc}
\hline Fixed effects & Estimate & SE & $z$ & $P$ \\
\hline (Intercept) & -1.23 & 1.36 & - & - \\
Male career stage & & & & \\
$\quad$ Uninvested males (reference category) & - & - & - & - \\
$\quad$ Dominant unlikely sire & 0.65 & 0.50 & - & - \\
$\quad$ Subordinate likely sire & 0.95 & 0.40 & - & - \\
$\quad$ Dominant likely sire & 0.35 & 0.45 & - & - \\
Residency & & & & \\
$\quad$ Immigrant & $-\mathbf{0 . 6 6}$ & $\mathbf{0 . 3 5}$ & $\mathbf{- 1 . 8 6}$ & $\mathbf{0 . 0 6 4}$ \\
$\quad$ Emigrant & 0.09 & 0.36 & 0.25 & 0.801 \\
Seasonal factors & & & & \\
$\quad$ Month following first birth & $\mathbf{1 . 3 9}$ & $\mathbf{0 . 5 7}$ & $\mathbf{2 . 4 3}$ & $\mathbf{0 . 0 1 5}$ \\
$\quad$ Number of infants & -0.32 & 0.17 & - & - \\
$\quad$ Seasonal habitat productivity & 1.65 & 1.14 & 1.44 & 0.150 \\
$\quad$ Mating season & 0.45 & 0.33 & 1.34 & 0.180 \\
Intensity of use & -0.08 & 0.12 & -0.65 & 0.514 \\
Distance to home range centre & -0.03 & 0.05 & -0.66 & 0.510 \\
Relative group size & 0.03 & 0.05 & - & - \\
Interactions & & & & \\
$\quad$ Number of infants * Relative group size & -0.03 & 0.02 & -1.73 & 0.084 \\
$\quad$ Number of infants * Dominant unlikely sire & 0.04 & 0.38 & 0.10 & 0.920 \\
$\quad$ Number of infants * Subordinate likely sire & 0.38 & 0.21 & 1.76 & 0.079 \\
$\quad$ Number of infants * Dominant likely sire & $\mathbf{0 . 5 0}$ & $\mathbf{0 . 2 0}$ & $\mathbf{2 . 4 3}$ & $\mathbf{0 . 0 1 5}$ \\
\hline
\end{tabular}

765 The final model was significantly different from the null model containing only an intercept term and individual

766 nested in group as random effects (likelihood ratio test: $N=351, \chi^{2}=80.43, P<0.001, R_{\text {GLMM(c) }}^{2}=0.23$ ). Male

767 career stage was always compared to uninvested males as a reference category. The removed nonsignificant

768 interactions were those between male career stage and whether it was the month following the first birth of the

769 season or not $\left(N=351, \chi^{2}=0.91, P=0.635\right)$, male career stage and seasonal habitat productivity $\left(N=351, \chi^{2}=\right.$

$7702.57, P=0.463)$ and male career stage and mating season $\left(N=351, \chi^{2}=1.24, P=0.742\right)$. Significant predictors

771 are presented in bold and trends are italicized. 
774 Factors affecting the probability that males were aggressive during between-group conflicts (aggression as a

775 homogeneous phenomenon), with all likely sires pooled, regardless of their rank.

\begin{tabular}{lcccc}
\hline Fixed effects & Estimate & SE & $z$ & $P$ \\
\hline (Intercept) & -1.44 & 1.40 & - & - \\
Male career stage & & & & - \\
$\quad$ Uninvested males (reference category) & - & - & - & - \\
$\quad$ Dominant unlikely sire & 0.59 & 0.53 & - & - \\
$\quad$ All likely sires (pooled) & 0.65 & 0.38 & - & \\
Residency & & & & \\
$\quad$ Immigrant & -0.70 & 0.36 & -1.92 & 0.051 \\
$\quad$ Emigrant & 0.10 & 0.37 & 0.27 & 0.787 \\
Seasonal factors & & & & \\
$\quad$ Month Following first birth & $\mathbf{1 . 3 8}$ & $\mathbf{0 . 5 8}$ & $\mathbf{2 . 3 7}$ & $\mathbf{0 . 0 1 8}$ \\
$\quad$ Number of infants & -0.32 & 0.17 & - & - \\
$\quad$ Seasonal habitat productivity & 1.70 & 1.17 & 1.46 & 0.146 \\
$\quad$ Mating season & 0.45 & 0.34 & 1.34 & 0.180 \\
Intensity of use & -0.06 & 0.12 & -0.49 & 0.622 \\
Distance to home range centre & -0.03 & 0.05 & -0.60 & 0.547 \\
Relative group size & 0.05 & 0.05 & - & - \\
Interactions & & & & \\
$\quad$ Number of infants * Relative group size & -0.03 & 0.02 & -1.91 & 0.056 \\
$\quad$ Number of infants * Dominant unlikely sire & 0.04 & 0.39 & 0.12 & 0.908 \\
$\quad$ Number of infants * All likely sires & $\mathbf{0 . 4 3}$ & $\mathbf{0 . 1 9}$ & $\mathbf{2 . 2 6}$ & $\mathbf{0 . 0 2 4}$ \\
\hline
\end{tabular}

776 The final model was significantly different from the null model containing only an intercept term and individual

777 nested in group as random effects (likelihood ratio test: $N=351, \chi^{2}=79.56, P<0.001, R_{G L M M(c)}^{2}=0.24$ ). Male

778 career stage was always compared to uninvested males as a reference category. Significant predictors are

779 presented in bold and trends are italicized.

780

781

782

783

784

785

786 
Factors affecting the probability that males exhibited defensive (reactive) aggression to protect group members during between-group conflicts, after nonsignificant interaction terms were removed from the model

\begin{tabular}{lcccc}
\hline Fixed effects & Estimate & SE & $Z$ & $P$ \\
\hline (Intercept) & -5.50 & 2.26 & - & - \\
Male career stage & & & & \\
$\quad$ Uninvested males (reference category) & - & - & - & - \\
$\quad$ Dominant unlikely sire & -0.24 & 0.82 & -0.29 & 0.770 \\
$\quad$ Subordinate likely sire & 1.14 & 0.55 & $\mathbf{2 . 0 7}$ & $\mathbf{0 . 0 3 8}$ \\
$\quad$ Dominant likely sire & 1.11 & 0.60 & 1.83 & 0.067 \\
Residency & & & & \\
$\quad$ Immigrant & -0.00 & 0.56 & -0.00 & 0.998 \\
$\quad$ Emigrant & -0.02 & 0.56 & -0.03 & 0.978 \\
Seasonal factors & & & & \\
$\quad$ Month following first birth & 0.32 & 0.78 & 0.41 & 0.685 \\
$\quad$ Number of infants & 0.08 & 0.09 & 0.89 & 0.375 \\
$\quad$ Seasonal habitat productivity & 1.66 & 1.89 & 0.88 & 0.380 \\
$\quad$ Mating season & 0.27 & 0.53 & 0.52 & 0.607 \\
Intensity of use & -0.12 & 0.22 & -0.57 & 0.570 \\
Distance to home range centre & 0.37 & 0.26 & 1.43 & 0.153 \\
Relative group size & -0.02 & 0.08 & -0.24 & 0.809 \\
\hline
\end{tabular}

The final model was significantly different from the null model containing only group and individual as random

effects (likelihood ratio test: $N=345, \chi^{2}=23.15, P=0.026, R_{\text {GLMM(c) }}^{2}=0.53$ ). Male career stage was always compared to uninvested males as a reference category. The removed nonsignificant interactions were those between male career stage and seasonal habitat productivity $\left(N=345, \chi^{2}=1.91, P=0.591\right)$, male career stage and mating season $\left(N=345, \chi^{2}=4.66, P=0.198\right)$ and relative group size and the number of infants $\left(N=345, \chi^{2}=\right.$ $1.32, P=0.251)$. The model failed to converge when the interactions between male career stage and the number of infants and male career stage and whether it was the month following the first birth of the season or not were included; therefore, we could not evaluate the significance of these interactions. Significant predictors are presented in bold and trends are italicized. 
803 Factors affecting the probability that males exhibited defensive (reactive) aggression to protect group members

804 during between-group conflicts, with all likely sires pooled

\begin{tabular}{lcccc}
\hline Fixed effects & Estimate & SE & $z$ & $P$ \\
\hline (Intercept) & -5.52 & 2.23 & - & - \\
Male career stage & & & & \\
$\quad$ Uninvested males (reference category) & - & - & - & - \\
$\quad$ Dominant unlikely sire & -0.24 & 0.82 & -0.30 & 0.767 \\
$\quad$ All likely sires (pooled) & $\mathbf{1 . 1 3}$ & $\mathbf{0 . 4 8}$ & $\mathbf{2 . 3 6}$ & $\mathbf{0 . 0 1 8}$ \\
Residency & & & & \\
$\quad$ Immigrant & -0.00 & 0.56 & -0.00 & 0.997 \\
$\quad$ Emigrant & 0.01 & 0.56 & 0.03 & 0.979 \\
Seasonal factors & & & & \\
$\quad$ Month following first birth & 0.32 & 0.77 & 0.41 & 0.679 \\
$\quad$ Number of infants & 0.08 & 0.09 & 0.89 & 0.375 \\
$\quad$ Seasonal habitat productivity & 1.68 & 1.87 & 0.90 & 0.371 \\
$\quad$ Mating season & 0.27 & 0.53 & 0.52 & 0.604 \\
Intensity of use & -0.13 & 0.21 & -0.58 & 0.559 \\
Distance to home range centre & 0.37 & 0.25 & 1.51 & 0.130 \\
Relative group size & -0.02 & 0.07 & -0.24 & 0.810 \\
\hline
\end{tabular}

805 The final model was significantly different from the null model containing only group and individual as random

806 effects (likelihood ratio test: $N=345, \chi^{2}=23.15, P=0.017, R_{G L M M(c)}^{2}=0.53$ ). Male career stage was always

807 compared to uninvested males as a reference category. Significant predictors are presented in bold and trends

808 are italicized.

809

810

811

812

813

814

815

816

817 
819 Factors affecting the probability that males repelled prospecting extragroup males during between-group

820 conflicts, after nonsignificant interaction terms were removed from the model

\begin{tabular}{lcccc}
\hline Fixed effects & Estimate & SE & $z$ & $P$ \\
\hline (Intercept) & -3.81 & 2.41 & - & - \\
Male career stage & & & & \\
$\quad$ Uninvested males (reference category) & - & - & - & - \\
$\quad$ Dominant unlikely sire & 0.47 & 0.88 & 0.54 & 0.590 \\
$\quad$ Subordinate likely sire & 1.15 & 0.66 & 1.75 & 0.080 \\
$\quad$ Dominant likely sire & 1.71 & 0.65 & $\mathbf{2 . 6 4}$ & $\mathbf{0 . 0 0 8}$ \\
Residency & & & & \\
$\quad$ Immigrant & -1.29 & 0.83 & -1.57 & 0.118 \\
$\quad$ Emigrant & 0.48 & 0.62 & 0.78 & 0.438 \\
Seasonal factors & & & & \\
$\quad$ Month following first birth & -0.56 & 1.17 & -0.48 & 0.632 \\
$\quad$ Number of infants & -0.16 & 0.13 & -1.23 & 0.220 \\
$\quad$ Seasonal habitat productivity & 3.49 & 2.04 & 1.71 & 0.088 \\
$\quad$ Mating season & -0.16 & 0.64 & -0.24 & 0.809 \\
Intensity of use & -0.05 & 0.21 & -0.24 & 0.813 \\
Distance to home range centre & -0.07 & 0.09 & -0.74 & 0.459 \\
Relative group size & 0.04 & 0.08 & 0.49 & 0.625 \\
\hline
\end{tabular}

821 The final model was significantly different from the null model containing only group and individual as random

822 effects (likelihood ratio test: $N=351, \chi^{2}=34.64, P<0.001, R_{G L M M(c)}^{2}=0.26$ ). Male career stage was always 823 compared to uninvested males as a reference category. The removed nonsignificant interactions were those 824 between male career stage and the number of infants $\left(N=351, \chi^{2}=1.21, P=0.752\right)$, male career stage and 825 seasonal habitat productivity $\left(N=351, \chi^{2}=1.32, P=0.725\right)$, male career stage and mating season $\left(N=351, \chi_{3}^{2}=\right.$ $8261.70, P=0.637)$ and relative group size and the number of infants $\left(N=351, \chi^{2}=0.02, P=0.877\right)$. The model 827 failed to converge when the interaction between male career stage and whether it was the month following the 828 first birth of the season or not was included; therefore, we could not evaluate the significance of this term. 829 Significant predictors are presented in bold and trends are italicized. 
835 Factors affecting the probability that males repelled prospecting extragroup males during between-group

836 conflicts, with all likely sires pooled

\begin{tabular}{lcccc}
\hline Fixed effects & Estimate & SE & $z$ & $P$ \\
\hline (Intercept) & -3.78 & 2.41 & - & - \\
Male career stage & & & & \\
$\quad$ Uninvested males (reference category) & - & - & - & - \\
$\quad$ Dominant unlikely sire & 0.50 & 0.88 & 0.57 & 0.566 \\
$\quad$ All likely sires (pooled) & 1.42 & $\mathbf{0 . 5 6}$ & $\mathbf{2 . 5 1}$ & $\mathbf{0 . 0 1 2}$ \\
Residency & & & & \\
$\quad$ Immigrant & -1.28 & 0.83 & -1.56 & 0.120 \\
$\quad$ Emigrant & 0.42 & 0.62 & 0.68 & 0.494 \\
Seasonal factors & & & & \\
$\quad$ Month following first birth & -0.50 & 1.16 & -0.43 & 0.666 \\
$\quad$ Number of infants & -0.15 & 0.13 & -1.19 & 0.236 \\
$\quad$ Seasonal habitat productivity & 3.46 & 2.02 & 1.71 & 0.087 \\
$\quad$ Mating season & -0.17 & 0.64 & -0.27 & 0.786 \\
Intensity of use & -0.05 & 0.21 & -0.23 & 0.819 \\
Distance to home range centre & -0.07 & 0.09 & -0.81 & 0.416 \\
Relative group size & 0.02 & 0.07 & 0.22 & 0.827 \\
\hline
\end{tabular}

837 The final model was significantly different from the null model containing only group and individual as random

838 effects (likelihood ratio test: $N=351, \chi^{2}=33.88, P<0.001, R_{\text {GLMM(c) }}^{2}=0.26$ ). Male career stage was always

839 compared to uninvested males as a reference category. Significant predictors are presented in bold and trends

840 are italicized.

841

842

843

844

845

846

847

848 
850 Factors affecting the probability that males exhibited proactive aggression (proactive aggression without a

851 female partner) during between-group conflicts, after nonsignificant interaction terms were removed from the

852 model

\begin{tabular}{lcccc}
\hline Fixed effects & Estimate & SE & $z$ & $P$ \\
\hline (Intercept) & -2.18 & 3.26 & - & - \\
Male career stage & & & & \\
$\quad$ Uninvested males (reference category) & - & - & - & - \\
$\quad$ Dominant unlikely sire & 1.78 & 1.47 & 1.21 & 0.226 \\
$\quad$ Subordinate likely sire & $\mathbf{2 . 3 6}$ & $\mathbf{1 . 1 6}$ & $\mathbf{2 . 0 4}$ & $\mathbf{0 . 0 4 1}$ \\
$\quad$ Dominant likely sire & $\mathbf{2 . 5 1}$ & $\mathbf{1 . 1 6}$ & $\mathbf{2 . 1 6}$ & $\mathbf{0 . 0 3 1}$ \\
Residency & & & & \\
$\quad$ Immigrant & - & - & - & - \\
$\quad$ Emigrant & -0.57 & 1.15 & -0.50 & 0.619 \\
Seasonal factors & & & & \\
$\quad$ Month following first birth & 0.78 & 0.92 & 0.86 & 0.392 \\
$\quad$ Number of infants & 0.03 & 0.12 & 0.25 & 0.804 \\
$\quad$ Seasonal habitat productivity & -1.81 & 3.09 & -0.58 & 0.559 \\
$\quad$ Mating season & -1.25 & 1.17 & -1.07 & 0.283 \\
Intensity of use & -0.06 & 0.31 & -0.18 & 0.857 \\
Distance to home range centre & -0.25 & 0.16 & -1.61 & 0.108 \\
Relative group size & 0.02 & 0.09 & 0.20 & 0.838 \\
\hline
\end{tabular}

853 The model failed to converge when the factor 'Immigrant' was included because recent immigrants were never

854 seen to exhibit this type of aggression. The final model excluding 'Immigrant' was significantly different from the 855 null model containing only group and individual as random effects (likelihood ratio test: $N=351, \chi^{2}=41.00, P<$ $\left.8560.001, R_{\text {GLMM(c) }}^{2}=0.50\right)$. Male career stage was always compared to uninvested males as a reference category.

857 The interaction between relative group size and the number of infants was nonsignificant and was subsequently

858 removed from the model $\left(N=351, \chi_{1}^{2}=0.20, P=0.657\right)$. The model failed to converge when the interactions 859 between male career stage and whether it was the month following the first birth of the season or not, male 860 career stage and the number of infants, male career stage and seasonal habitat productivity and male career 861 stage and mating season were included; therefore, we could not evaluate the significance of these interactions. 862 Significant predictors are presented in bold and trends are italicized. 
866 Factors affecting the probability that males supported female instigators during between-group conflicts, after

867 nonsignificant interaction terms were removed from the model

\begin{tabular}{lcccc}
\hline Fixed effects & Estimate & SE & $z$ & $P$ \\
\hline (Intercept) & 0.32 & 2.58 & - & - \\
Male career stage & & & & \\
$\quad$ Uninvested males (reference category) & - & - & - & - \\
$\quad$ Dominant unlikely sire & -4.00 & 2.53 & - & - \\
$\quad$ Subordinate likely sire & 0.24 & 1.78 & - & - \\
$\quad$ Dominant likely sire & -2.65 & 2.01 & - & - \\
Residency & & & & \\
$\quad$ Immigrant & -1.21 & 0.54 & $-\mathbf{2 . 2 3}$ & $\mathbf{0 . 0 2 6}$ \\
$\quad$ Emigrant & 0.31 & 0.53 & 0.60 & 0.552 \\
Seasonal factors & & & & \\
$\quad$ Month following first birth & 1.43 & 0.86 & 1.66 & 0.098 \\
$\quad$ Number of infants & -0.27 & 0.18 & -1.52 & 0.129 \\
$\quad$ Seasonal habitat productivity & -2.63 & 3.11 & - & - \\
$\quad$ Mating season & 1.41 & $\mathbf{0 . 5 0}$ & $\mathbf{2 . 8 0}$ & $\mathbf{0 . 0 0 5}$ \\
Intensity of use & -0.30 & 0.22 & -1.41 & 0.160 \\
Distance to home range centre & 0.07 & 0.07 & 0.94 & 0.349 \\
Relative group size & 0.06 & 0.06 & 1.04 & 0.299 \\
Interactions & & & & \\
$\quad$ Habitat productivity * Dominant unlikely sire & $\mathbf{1 1 . 6 9}$ & $\mathbf{5 . 0 9}$ & $\mathbf{2 . 3 0}$ & $\mathbf{0 . 0 2 2}$ \\
$\quad$ Habitat productivity * Subordinate likely sire & 2.12 & 4.37 & 0.49 & 0.628 \\
$\quad$ Habitat productivity * Dominant likely sire & 8.90 & 4.73 & 1.88 & 0.060 \\
\hline The
\end{tabular}

868

869

870

871

872

873

874 875

876

The final model was significantly different from the null model containing only group and individual as random

effects (likelihood ratio test: $N=340, \chi^{2}=65.38, P<0.001, R_{\text {GLMM(c) }}^{2}=0.38$ ). Male career stage was always

compared to uninvested males as a reference category. The removed nonsignificant interactions were those

between male career stage and whether it was the month following the first birth of the season or not $(N=340$,

$\left.\chi^{2}=1.00, P=0.601\right)$, male career stage and the number of infants in the group $\left(N=340, \chi^{2}=1.46, P=0.692\right)$,

male career stage and mating season $\left(N=340, \chi^{2}=4.23, P=0.237\right)$ and relative group size and the number of infants $\left(N=340, \chi^{2}=0.00, P=0.969\right)$. Significant predictors are presented in bold and trends are italicized. 
878 Factors affecting the probability that males supported female instigators during between-group conflicts, with

879 all dominant males pooled, regardless of their likelihood of paternity

\begin{tabular}{lcccc}
\hline Fixed effects & Estimate & SE & $z$ & $P$ \\
\hline (Intercept) & 0.31 & 2.59 & - & - \\
Male career stage & & & & \\
$\quad$ Uninvested males (reference category) & - & - & - & - \\
$\quad$ All dominant males (pooled) & -3.22 & 1.74 & - & - \\
$\quad$ Subordinate likely sire & -0.15 & 1.76 & - & - \\
Residency & & & & \\
$\quad$ Immigrant & $-\mathbf{1 . 1 9}$ & $\mathbf{0 . 5 4}$ & $\mathbf{- 2 . 2 2}$ & $\mathbf{0 . 0 2 6}$ \\
$\quad$ Emigrant & 0.38 & 0.51 & 0.74 & 0.458 \\
Seasonal factors & & & & \\
$\quad$ Month following first birth & 1.48 & 0.86 & 1.74 & 0.083 \\
$\quad$ Number of infants & -0.28 & 0.18 & -1.56 & 0.118 \\
$\quad$ Seasonal habitat productivity & -2.65 & 3.13 & - & - \\
$\quad$ Mating season & $\mathbf{1 . 4 2}$ & $\mathbf{0 . 5 0}$ & $\mathbf{2 . 8 5}$ & $\mathbf{0 . 0 0 4}$ \\
Intensity of use & -0.31 & 0.22 & -1.42 & 0.155 \\
Distance to home range centre & 0.07 & 0.07 & 1.03 & 0.303 \\
Relative group size & 0.05 & 0.06 & 0.84 & 0.403 \\
Interactions & 0.07 & 0.06 & 1.11 & 0.269 \\
$\quad$ Habitat productivity * All dominant males & $\mathbf{1 0 . 2 4}$ & $\mathbf{4 . 0 3}$ & $\mathbf{2 . 5 4}$ & $\mathbf{0 . 0 1 1}$ \\
$\quad$ Habitat productivity * Subordinate likely sire & 2.21 & 4.39 & 0.50 & 0.614 \\
\hline
\end{tabular}

880 The final model was significantly different from the null model containing only group and individual as random

881 effects (likelihood ratio test: $N=340, \chi^{2}=65.10, P<0.001, R_{G L M M(c)}^{2}=0.38$ ). Male career stage was always

882 compared to uninvested males as a reference category. Significant predictors are presented in bold and trends

883 are italicized. 